\title{
PELAKSANAAN ASUHAN SAYANG IBU PADA PROSES PERSALINAN DI BLUD RUMAH SAKIT KABUPATEN KONAWE
}

\author{
Murti Wuryani \\ ${ }^{1}$ Akbid Yayasan Pendidikan Konawe, Jl. DII Panjaitan No. 217 Kel. Tuoy Kec. Unaaha \\ Kab. Konawe - Sulawesi Tenggara, 082242226689 \\ E-mail : murtiinara@gmail.com
}

\begin{abstract}
ABSTRAK
Asuhan sayang Ibu adalah asuhan yang saling menghargai budaya, kepercayaan dari keinginan sang ibu pada asuhan yang aman selama proses persalinan serta melibatkan ibu dan keluarga sebagai pembuat keputusan, tidak emosional dan sifatnya mendukung dan diharapkan dapat menurunkan angka kematian maternal dan neonatal. Berdasarkan studi pendahuluan di Ruang Bersalin BLUD Rumah Sakit Kabupaten Konawe ditemukan data dari Januari sampai dengan Maret 2019 jumlah pasien bersalin yaitu 218 ibu, yang terdiri dari 92 ibu melahirkan normal dan 126 ibu melahirkan section caesarea (SC). Tujuan penelitian ini adalah untuk mengetahui hubungan pelaksanaan Asuhan sayang Ibu dengan proses persalinan ruang bersalin BLUD Rumah Sakit Kabupaten Konawe. Jenis penelitian yang digunakan adalah penelitian analitik dengan rancangan cross sectional. Sampel dalam penelitian ini yaitu ibu bersalin berjumlah 68 orang. Instrumen yang digunakan adalah kuesioner. Ada hubungan yang signifikan antara pelaksanaan Asuhan sayang Ibu dengan proses persalinan di Ruang Bersalin BLUD Rumah Sakit Kabupaten Konawe $(\rho=0.000)$. Responden yang diberikan Asuhan sayang Ibu mempunyai kemungkinan 2,6 kali berisiko melahirkan normal di bandingkan dengan ibu yang melahirkan dengan SC (RP=2,6 Cl 95\%). Diharapkan bidan dan calon bidan dapat lebih kompeten dalam melaksanakan prosedur pelaksanaan asuhan sayang ibu demi meningkatkan pelaksanaan asuhan sayang ibu pada ibu bersalin.
\end{abstract}

KataKunci : asuhan sayang ibu ; proses persalinan

\section{ABSTRACT}

Mother Caring is an upbringing that respects culture, trusts from the wishes of the mother on care that is safe during labor and involves the mother and family as decision makers, not emotional and in a supportive nature and is expected to reduce maternal and neonatal mortality. Based on a preliminary study in the Maternity Room at the BLUD Konawe District Hospital, data were found from January to March 2019, the number of maternity patients was 218 mothers, consisting of 92 normal delivery mothers and 126 mothers giving birth to the Caesarea (SC) section. The purpose of this study was to determine the relationship between the implementation of Mother Caring and the delivery process of the delivery room at the Konawe Regency BLUD Hospital. The type of research used analytical research with a cross sectional design. The sample in this study was 68 mothers giving birth. The instrument used was a questionnaire. There is a significant relationship between the implementation of Mother Caring and the delivery process at the Maternity Hospital BLUD Konawe District Hospital $(\rho=$ 0.000). Respondents who were given Mother Caring had a 2.6 times risk of having a normal delivery compared to mothers who gave birth with $\mathrm{SC}(\mathrm{RP}=2.6 \mathrm{Cl} 95 \%)$. It is expected that midwives and prospective midwives can be more competent in carrying out procedures for implementing maternal care in order to improve the implementation of care for mothers to give birth to mothers.

Keywords: mother caring, labor 


\section{LATAR BELAKANG}

Derajat kesehatan seseorang, kelompok atau masyarakat dinyatakan dengan indikator umur harapan hidup waktu lahir, Angka Kematian Bayi (AKB), Angka Kematian Balita (AKABA), Angka Kematian Ibu (AKI), angka kesakitan dan keadaan status gizi kesehatan. Kematian saat melahirkan biasanya menjadi faktor utama mortalitas wanita muda pada masa puncak produktivitasnya. Angka Kematian Ibu (AKI) pada periode 1991-2007 mengalami penurunan dari 390 menjadi 228 per 100.000 kelahiran hidup, pada SDKI 2012 angka kematian ibu kembali naik menjadi 359 per 100.000 kelahiran hidup dan pada tahun 2015 AKI menunjukkan penurunan yaitu 305 kematian per 100.000 kelahiran hidup (Kemenkes, 2017).

Upaya-upaya World Health Organization (WHO) dalam menurunkan Angka Kematian Ibu (AKI) dengan meluncurkan strategis Making Pregnancy Safer (MPS) yang mana pada dasarnya Making Pregnancy Safer (MPS) adalah menempatkan Safe Motherhood sebagai prioritas utama dalam rencana pembangunan nasional dan internasional dan upaya tersebut dilanjutkan dengan Gerakan Sayang Ibu (GSI). Asuhan sayang ibu adalah asuhan yang saling menghargai budaya, kepercayaan dari keinginan sang ibu pada asuhan yang aman selama proses persalinan serta melibatkan ibu dan keluarga sebagai pembuat keputusan, tidak emosional dan sifatnya mendukung. Asuhan sayang ibu mengacu dalam kompetensi bidan di Indonesia, terutama standar kompetensi k-4 yaitu asuhan selama persalinan dan kelahiran, bidan harus mampu memberikan asuhan selama persalinan (Kemenkes, 2017).

Tujuan asuhan persalinan adalah memberikan dukungan, baik fisik maupun emosional, melakukan pengkajian, membuat diagnosis, mencegah komplikasi, menangani komplikasi, melakukan rujukan pada kasus yang tidak dapat ditangani sendiri, memberikan asuhan yang adekuat kepada ibu dengan intervensi minimal sesuai dengan tahap persalinannya, memperkecil resiko infeksi, memberitahu ibu dan keluarganya mengenai kemajuan persalinan, memberikan asuhan yang tepat untuk bayi segera setelah lahir, membantu ibu dalam pemberian ASI dini. Hasil penelitian menunjukkan bahwa jika para ibu diperhatikan dan diberi dukungan selama persalinan dan kelahiran bayi serta mengetahui dengan baik mengenai proses persalinan dan asuhan yang akan mereka terima, mereka akan mendapatkan rasa aman dan keluaran yang lebih baik (Kusumaningsih, 2013).

Berdasarkan studi pendahuluan yang telah dilakukan pada Maret 2019 di Ruang Bersalin BLUD Rumah Sakit Kabupaten Konawe ditemukan data dari Januari sampai dengan Maret 2019 jumlah pasien bersalin yaitu 218 ibu. Yang terdiri dari 92 ibu melahirkan normal dan 126 ibu melahirkan Seksio Sesarea (SC). Data tersebut menunjukkan bahwa proses persalinan dengan cara SC lebih banyak daripada persalinan normal (Rekam Medis, Maret 2019).

\section{METODE}

Penelitian ini telah dilaksanakan di BLUD RS Konawe pada bulan April 2019. Jenis penelitian yang digunakan adalah penelitian analitik dengan pendekatan cross sectional. Populasi dalam penelitian ini adalah semua ibu bersalin baik persalinan normal maupun SC di BLUD RS Konawe periode Januari-Maret tahun 2019, jumlah sampel 68 orang dengan metode pengambilan sampel teknik accidental sampling. Instrumen yang digunakan adalah kuesioner. Variabel yang diteliti yaitu variabel independent asuhan sayang ibu dan variabel dependen yaitu proses persalinan.

\section{HASIL}

Analisa bivariat dilakukan untuk melihat hubungan antara variabel independen pelaksanaan Mother Caring dengan variabel dependen yaitu proses persalinan. Uji analisis statistik yang digunakan adalah chi-square pada tingkat kepercayaan ( $=0.05)$, dengan menggunakan komputerisasi dan program Statistical Product and Service Solutions (SPSS) dapat dilihat pada tabel 1. 
Tabel 1. Hubungan Antara Pelaksanaan mother caring dengan Proses Persalinan di Ruang Bersalin BLUD Rumah Sakit Kabupaten Konawe

\begin{tabular}{|c|c|c|c|c|c|c|c|}
\hline \multirow{3}{*}{$\begin{array}{l}N \\
0\end{array}$} & \multirow{3}{*}{$\begin{array}{l}\text { Asuhan } \\
\text { Sayang } \\
\text { Ibu }\end{array}$} & \multicolumn{4}{|c|}{ Proses Persalinan } & \multirow{2}{*}{\multicolumn{2}{|c|}{ Jumlah }} \\
\hline & & \multicolumn{2}{|c|}{ Normal } & \multicolumn{2}{|c|}{$\begin{array}{c}\text { Abnorma } \\
\text { I/SC }\end{array}$} & & \\
\hline & & $\mathbf{N}$ & $\%$ & $\mathrm{n}$ & $\%$ & $\mathrm{~N}$ & $\%$ \\
\hline 1 & Diberikan & 30 & 44.1 & 10 & 14.7 & 40 & 58.8 \\
\hline 2 & $\begin{array}{l}\text { Idaak } \\
\text { diberikan }\end{array}$ & 8 & 11.8 & 20 & 29.4 & 28 & 41.2 \\
\hline & Jumlah & 38 & 55.9 & 30 & 44.1 & 68 & 100 \\
\hline & Pvalue & & & & 000 & & \\
\hline & $\mathrm{R} 95 \% \mathrm{Cl}$ & & & & 625 & & \\
\hline
\end{tabular}

Sumber : Data primer, diolah 2019

Hasil penelitian pada tabel 1. menunjukkan bahwa dari 40 responden yang mendapat asuhan sayang ibu terdapat 30 (44.1\%) responden yang bersalin dengan cara normal dan $10(14.7 \%)$ bersalin dengan cara SC. Sedangkan dari 28 responden yang tidak mendapat asuhan sayang ibu, terdapat 8 (11.8\%) responden yang bersalin normal dan $20(29.4 \%)$ bersalin dengan cara SC.

Hasil uji analisis chi square diperoleh $\rho_{\text {value }}$ lebih kecil dari nilai $\quad(0,000<0,05)$ yang berarti $\mathrm{Ha}$ diterima yaitu terdapat hubungan antara pelaksanaan Mother Caring dengan proses persalinan. Nilai OR $(95 \% \mathrm{Cl}) 2.6$ yang berarti responden yang diberikan asuhan sayang ibu 2.6 kali mempunyai kemungkinan melahirkan normal.

\section{PEMBAHASAN}

Hasil penelitian tentang hubungan pelaksanaan Asuhan Sayang Ibu dengan proses persalinan di ruang bersalin BLUD RS Konawe, maka diperoleh hasil yakni ada hubungan yang signifikan antara pelaksanaan asuhan sayang ibu dengan proses persalinan di ruang bersalin. Hasil penelitian ini sejalan dengan hasil penelitian yang dilakukan oleh Herly Kartini Tambuwun (2014) di Puskesmas Kolongan Kecamatan Kalawat Kabupaten Minahasa Utara yang menemukan bahwa ibuibu bersalin yang dilakukan asuhan sayang ibu sebagian besar persalinannya normal (58\%) setelah diberi asuhan sayang ibu, sedangkan
$21 \%$ responden yang tidak diberi Asuhan Sayang Ibu mengalami partus tidak normal.

Pelaksanaan asuhan sayang ibu yang mendasar atau menjadi prinsip dalam pemberian asuhan sayang ibu dalam proses persalinan meliputi pemberian dukungan emosional, pemberian cairan dan nutrisi, keleluasan untuk miksi dan defekasi, serta pencegahan infeksi. Semua hal tersebut digunakan sebagai antisipasi untuk menghindari terjadinya partus lama, partus tidak maju dan partus yang dirujuk. Asuhan sayang ibu adalah program yang direncanakan pemerintah untuk mengurangi tingginya angka kematian dan kesakitan para ibu yang diakibatkan oleh komplikasi kehamilan dan kelahiran (Lailiyana, 2012).

Asuhan sayang ibu menghormati kenyataan bahwa kehamilan dan persalinan merupakan proses alamiah, maka intervensi dan pengobatan yang tidak perlu untuk proses alamiah ini harus dihindari. Asuhan sayang ibu berpusat pada pasien dan bukan pada petugas kesehatan. Melaksanakan asuhan sayang ibu sangat bermanfaat bagi ibu untuk menghindari terjadinya partus lama, partus tidak maju dan partus macet. Jika dalam proses persalinan bidan tidak memperhatikan hal itu maka akan mempengaruhi kenyamanan ibu dalam menghadapi persalinan hal ini menyebabkan ibu kurang nyaman dan merasa gelisah sehingga berpengaruh terhadap proses persalinan (Risvianti, 2014).

Memasuki kala 1 fase aktif, sebagian besar pasien akan mengalami penurunan stamina dan mudah lelah. Saat ini yang harus dilakukan oleh bidan adalah menerapkan asuhan sayang ibu yaitu Memberikan dukungan mental, memberikan rasa percaya diri kepada ibu, serta berusaha memberi rasa nyaman dan aman, bidan melakukan tindakan pencegahan infeksi, Membimbing dan menganjurkan untuk mencoba posisi yang nyaman saat terjadi HIS, Menganjurkan ibu untuk makan dan minum saat tidak kontraksi. Menghargai dan memperbolehkan praktek-praktek tradisional yang tidak merugikan Menghindari tindakan yang berlebihan dan membahayakan serta 
menyiapkan rencana rujukan jika perlu (Herly, 2014).

BLUD Rumah Sakit Konawe menerapkan Asuhan sayang ibu terdiri dalam 4 fase yakni kala 1 sampai dengan kala 4. Dalam memberikan asuhan sayang ibu pada kala pertama petugas mendampingi ibu dengan membangun komunikasi tentang hal-hal yang berkaitan dengan proses persalinan mulai dari mensuport ibu, memberikan kesempatan kepada ibu untuk menentukan pendamping persalinan hingga semua yang terkait dalam membuat suasana nyaman ibu dalm menghadapi persalinan. Pada saat memasuki kala 2 (dua) petugas senantiasa mendampingi ibu dengan menjadi pendengar yang baik, memberikan infromasi tentang kemajuan persalinan, memotivasi ibu dengan setiap rangsangan sehingga semua upaya yang dilakukan semata-mata memberikan suasan dan rasa nyaman ibu saat persalinan. Pada kala 3 (tiga) petugas memfasilitasi ibu untuk memeluk bayinya, mengabarkan setiap perkembangan persalinan dan serta senaniata memantau kondisi ibu apakah dalam keadaan normal atau perlu pelayanan rujuk lanjut. Kala terakhir dalam asuhan sayang ibu adalah kala 4 (empat) dimana pada fase ini petugas terus memantau tanda-tanda vital kondisi ibu, memberikan edukasi dan konseling kepada ibu dalam perawatan diri dan bayi pasca persalinan, pemenuhan nutrisi ibu. Sehingga semua fase ini dilakukan oleh Petugas dan terus diberikan pendampingan hingga proses persalinan telah selesai secara menyeluruh. Banyak faktor yang melatarbelakangi asuhan sayang ibu ini berjalan dengan baik salah satunya dikarenakan tenaga kesehatannya sudah professional dan mengerti dengan tugasnya, pelaksanaan asuhan sayang ibu baik di lihat dari cara berbicara dengan responden dan dalam menangani persalinan tidak kasar, ramah dan bersahabat.

Masih ada asuhan sayang ibu yang belum optimal dilaksanakan di BLUD Rumah Sakit Konawe dikarenakan kondisi pasien/ibu yang berkunjung mayoritas yang telah masuk dalam fase aktif untuk persalinan, sehingga asuhan sayang ibu belum mampu diterapkan secara menyeluruh, akan tetapi pelayanan ibu bersalin tetap menjadi perhatian penuh petugas dalam menciptakan kondisi aman dan nyaman dalam menghadapi persalinan.

\section{KESIMPULAN DAN SARAN}

Ada hubungan yang signifikan antara pelaksanaan Asuhan Sayang Ibu dengan proses persalinan di ruang Bersalin BLUD Rumah Sakit Kabupaten Konawe. Nilai OR= 2.6 yang berarti responden yang diberikan asuhan sayang ibu 2.6 kali melahirkan normal.

Diharapkan dengan adanya publikasi hasil penelitian ini, petugas kesehatan bisa menerapkan asuhan sayang ibu kepada ibu bersalin secara menyeluruh agar dapat membantu menurunkan angka kematian ibu dan bayi.

\section{REFERENSI}

Kemenkes RI. (2017). Profil Kesehatan Indonesia Tahun 2017. Jakarta : Kementerian Kesehatan RI, ISBN 978-602-416-446-1

Kusumaningsih T. Puspa dan Yuliningsih A. (2013). Hubungan Pelaksanaan Asuhan Sayang Ibu dengan Kecemasan Proses Persalinan di BPM Hesti Utami Desa Grantung Kecamatan Bayan Kabupaten Purworejo.

Rekam Medis. Periode Jan-Mar (2019). Buku Laporan Persalinan BLUD RS Konawe. Konawe

Lailiyana, dkk. (2012). Buku Ajar Asuhan Kebidanan Persalinan. Jakarta: EGC.

Risvianti, Devi. (2014). Pelaksanaan Asuhan Sayang lbu Terhadap Proses Persalian Di RS Bangil Pasuruan.

Herly Kartini, dkk. (2014). Hubungan Pelaksanaan Asuhan Sayang Ibu dengan Lamanya Persalinan di Puskesmas Kolongan Kecamatan Kalawat Kabupaten Minahasa Utara. Jurnal Ilmiah Bidan, Volume 2 Nomor 1. Januari - Juni 2014, ISSN : 2339-1731. 
Wuryani , Pelaksanaan Asuhan Sayang Ibu Pada Proses Persalinan Di BLUD Rumah Sakit ....

SJKB, Vol. 6, No. 1, Juni 2019, 37-41

Ujiningtyas. (2009). Asuhan Keperawatan

Persalinan Normal. Jakarta

Salemba Medika. 